\title{
PERANCANGAN SISTEM INFORMASI KLAIM ASURANSI JIWA \\ MENGGUNAKAN Ms.VISUAL BASIC 6.0. PADA PT. ASURANSI JIWASRAYA KOTA BANDAR LAMPUNG
}

\author{
Ahmad Cucus \\ Program Studi Teknik Informatika \\ Fakultas Ilmu Komputer \\ Universitas Bandar Lampung \\ Jln. Z.A. Pagar Alam No.26 Labuhan Ratu Bandar Lampung 35142 \\ Telp. (0721) 701463, (0721) 701979 Fax. (0721) 701467 Web. www.ubl.ac.id
}

\begin{abstract}
Abstrak
Sistem informasi adalah suatu sistem didalam suatu organisasi yang mempertemukan kebutuhan pengelohan transaksi harian, pendukung operasi, bersifat manajerial, dan kegiatan strategi dari suatu organisasi dan menyediakan kepada pihak luar tertentu dengan laporan-laporan yang diperlukan. Adapun pelayanan yang diberikan oleh perusahaan tersebut berupa jasa asuransi jiwa yaitu dengan memberikan proteksi kepada nasabah dengan pelayanan prima dan selalu bertekat untuk senantiasa menepati janji, sesuai dengan apa yang dijajikan, namun dalam pengurusanya pada bagian klaim masih menggunakan waktu yang cukup lama baik dalam pencarian data nasabah, serta dalam pembuatan laporan klaim. Sehingga waktu yang ada tidak dapat dipergunakan dengan semaksimal mungkin dalam pemerosesan data klaim nasabah pada PT. Asuransi Jiwasraya .

Menanggapi permasalahan yang ada itulah, maka peneliti ingin membantu merancang sebuah sistem informasi klaim Asuransi jiwa dengan menggunakan bahasa pemrograman Ms. Visual Basic 6.0 yang berjudul : "Perancangan Sistem Informasi Klaim Asuransi Jiwa dengan menggunakan pemrograman Ms. Visual Basic 6.0 pada PT. Asuransi Jiwasraya Kota Bandar Lampung. “
\end{abstract}

\subsection{PENDAHULUAN}

\subsubsection{Identifikasi Masalah}

Setelah peneliti melakukan

pengamatan pada sistem saat ini, dengan menganalisis aliran prosedurnya, maka dapat dilihat bahwa sistem dalam pengurusanya pada bagian klaim masih menggunakan waktu yang cukup lama baik dalam pencarian data nasabah, serta dalam pembuatan laporan klaim. Sehingga waktu yang ada tidak dapat dipergunakan dengan semaksimal mungkin dalam pemerosesan data klaim nasabah pada PT. Asuransi Jiwasraya .

\subsubsection{Perumusan Masalah}

Berdasarkan identifikasi masalah tersebut, maka peneliti akan membuat sistem untuk mengatasi kendala-kendala tersebut, yaitu "Perancangan Sistem Informasi Klaim Asuransi Jiwa dengan menggunakan pemrograman Ms. Visual Basic 6.0 pada PT. Asuransi Jiwasraya Kota Bandar Lampung. "

\subsubsection{Batasan Masalah}

Perancangan program ini hanya sebatas mengenai klaim asuransi jiwa yang meliputi data nasabah, klaim dan laporan klaim pada PT.Asuransi Jiwasraya Kota Bandar Lampung.

\subsection{Manfaat Penelitian}

Program aplikasi yang dibuat dengan menggunakan bahasa pemrograman Ms. Visual Basic 6.0 diharapkan dapat memberi manfaat, diantaranya :

1. Menghasilkan Penginputan Data nasabah, Data Petugas,Data Premi serta Nomor Polis Nasabah.

2. Menghasilkan proses penghitungan Klaim nasabah..

3. Menghasilkan dalam pembuatan Laporan Klaim yang akan diberikan kepada Kepala kantor.

4. Dapat mempraktekkan ilmu yang selama ini diperoleh guna meningkatkan kemampuan dalam membuat program aplikasi.

\subsubsection{Tujuan}

Adapun tujuan dari penelitian tugas akhir ini adalah:

1. Peneliti ingin membantu pada kantor PT.Asuransi Jiwasraya dalam aktifitasnya 
khususnya dalam hal klaim asuransi jiwa agar lebih efektif dan efisien.

2. Peneliti ingin memperkenalkan suatu sistem untuk membuat laporan klaim dengan menggunakan bahasa pemrograman Ms. Visual Basic 6.0.

\subsection{LANDASAN TEORI}

Informasi ibarat darah yang mengalir di dalam suatu organisasi, sehingga informasi ini sangat penting.

\subsubsection{Definisi Informasi}

Informasi adalah hasil dari pengolahan data menjadi bentuk yang lebih berguna bagi penerimanya yang menggambarkan suatu kejadian-kejadian nyata dan dapat digunakan sebagai alat bantu untuk pengambilan suatu keputusan. (Teguh Wahyono, 2004: 3)

\subsubsection{Kualitas Informasi}

Tidak semua informasi itu berkualitas. Oleh karena itu, sudah seharusnya di lakukan penyaringan terhadap informasi yang beredar atau yang dapat di tangkap. Kualitas di tentukan oleh bebrapa faktor, yaitu :

1. Keakuratan dan Teruji Kebenarannya

Sebuah informasi dapat dikatakan akurat jika informasi tersebut tersebut tidak bias atau menyesatkan, bebas dari kesalahan-kesalahan dan harus jelas mencerminkan maksudnya. Ketidakakuratan sebuah informasi dapat terjadi karena sumber informasi (data) mengalami gangguan (noise) atau kesengajaan sehingga merusak atau merubah data-data asli tersebut.

2. Kesempurnaan Informasi

Untuk mendukung faktor pertama di atas, maka kesempurnaan informasi di sajikan lengkap tanpa pengurangan, penambahan, atau perubahan.

3. Tepat waktu (timeliness)

Bahwa informasi yang dihasilkan dari suatu proses pengolahan data, datangnya tidak boleh terlambat. Informasi yang terlambat tidak akan mempunyai nilai yang baik, sehingga kalau digunakan sebagai dasar dalam pengambilan keputusan dapat menimbulkan kesalahan dalam tindakan yang akan diambil.

4. Relevansi (relevancy)

Informasi akan memiliki nilai manfaat yang tinggi, jika informasi tersebut di terima oleh mereka yang membutuhkan, dan menjadi tidak berguna jika di berikan kepada mereka yang tidak membutuhkan.

5. Mudah dan Murah
Kini, cara dan biaya untuk memperoleh informasi juga menjadi bahan pertimbangan tersendiri. Bilamana cara dan biaya untuk memperoleh informasi sulit dan mahal, maka orang menjadi tidak berminat untuk memperolehnya atau mencari alternatif substitusinya. Biaya mahal yang dimaksud disini, jika bobot informasi tidak sebanding dengan biaya yang harus dikeluarkan. Dan melalui teknologi internet, kini orang atau perusahaan dapat memperoleh informasi dengan mudah dan murah. (Budi Stedjo DO, 2002 : 1617).

\section{Perancangan Dan Implementasi}

\subsection{Perancangan Sistem}

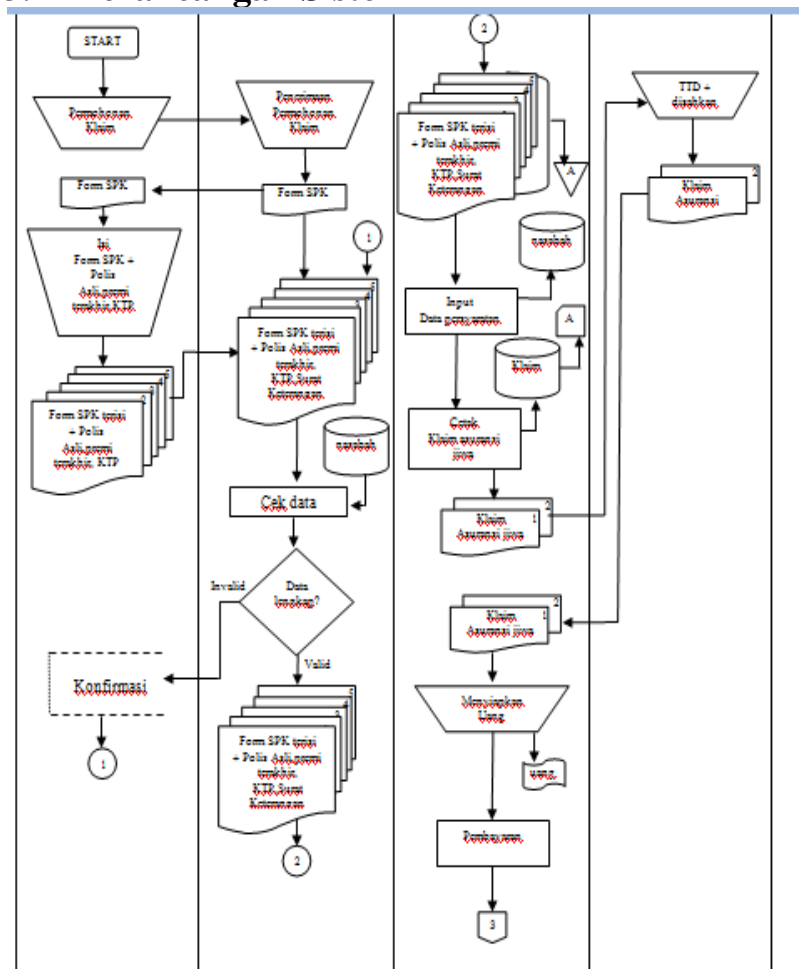




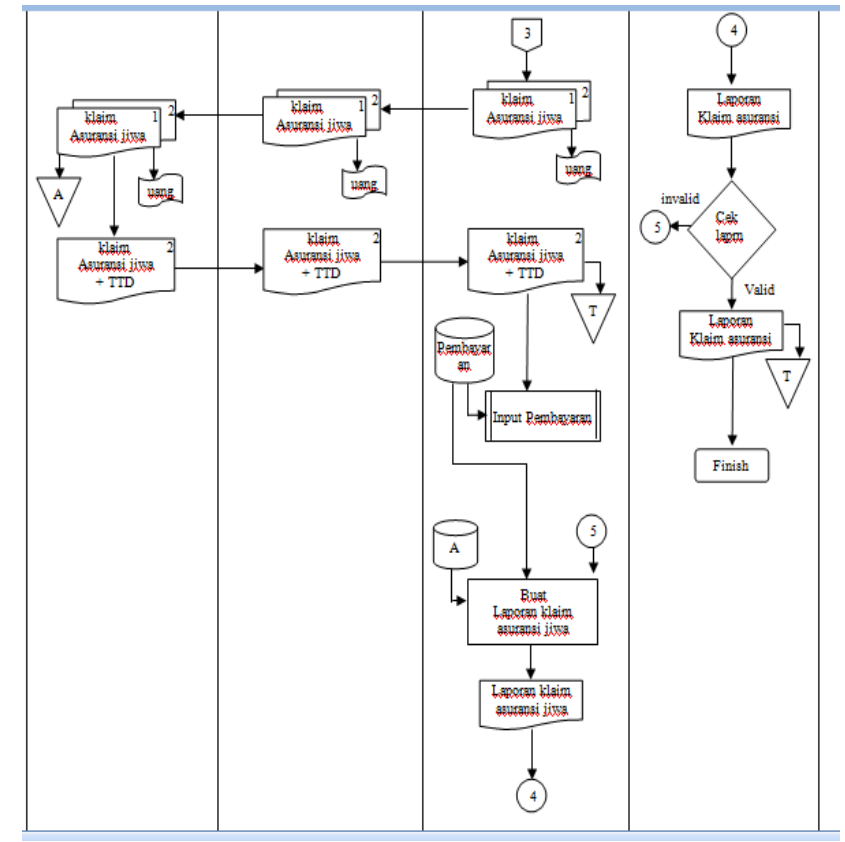

\subsection{DATA FLOW DIAGRAM}

3.2.1 Context Diagram Level 0 Sistem Informasi Klaim asuransi jiwa.

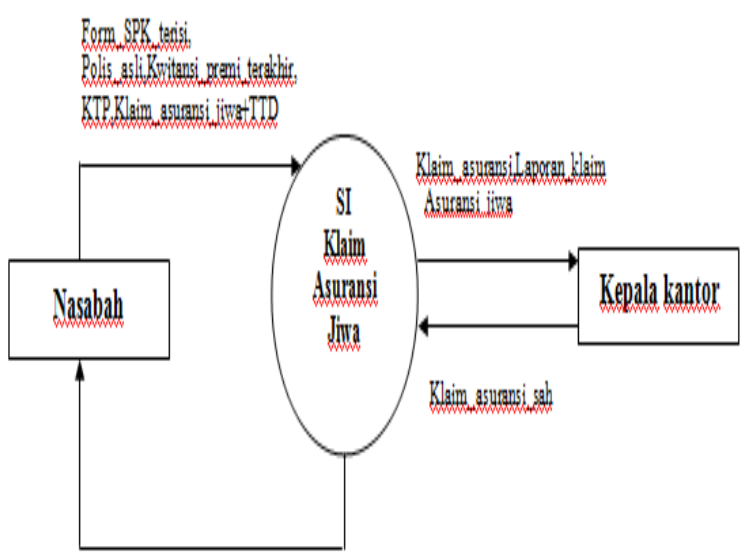

Bonfirmasi_dogangaggesh

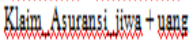

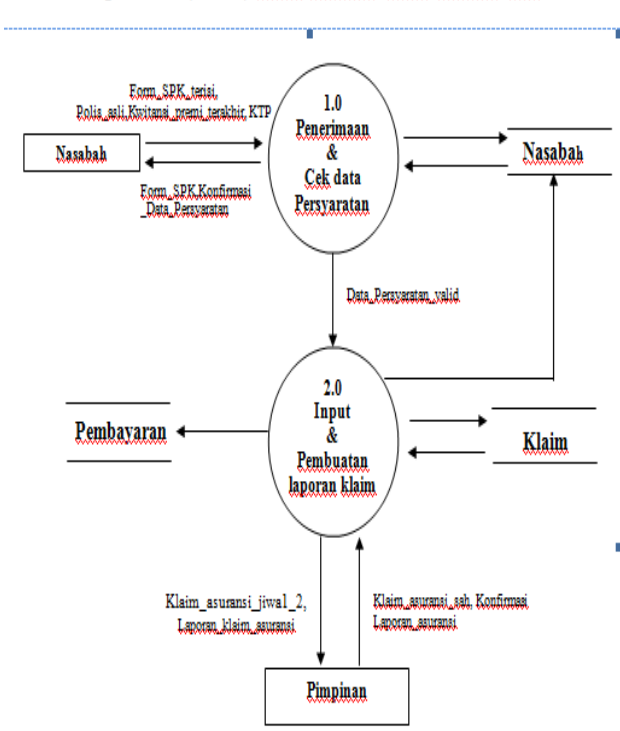

3.2.2 Diagram Detail ( level 2 ) Proses 1.0 Input data Persyaratan Asuransi

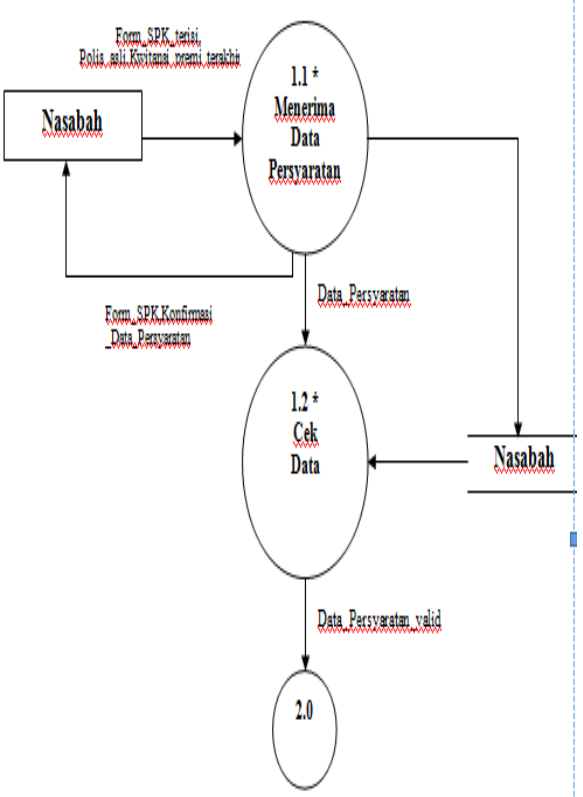

3.2.3 Diagram Detail ( level 2) Proses 2.0 Pengesahan Klaim asuransi jiwa

\subsubsection{Diagram Zero (Level 1) Sistem Informasi} Klaim Asuransi Jiwa 


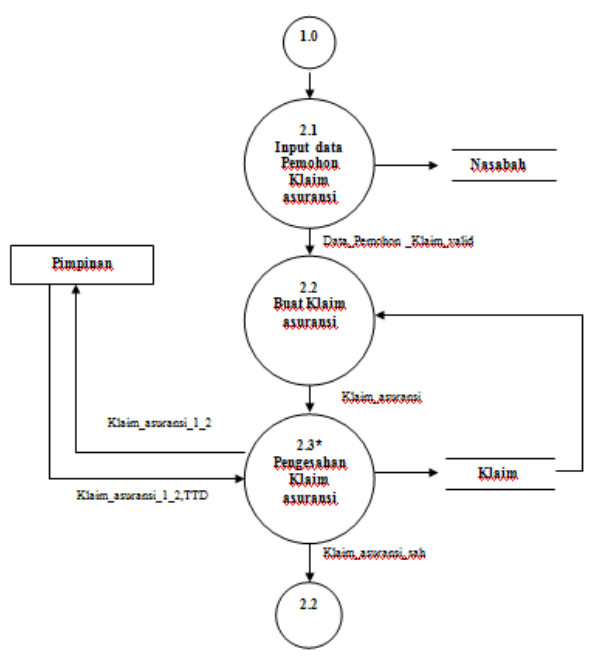

3.3 Relasi Antar Tabel Sistem Klaim Asuransi Jiwa Pada PT.Jiwasraya Kota Bandar lampung.

\subsection{ERD (Entity Relation Diagram) Usulan.}

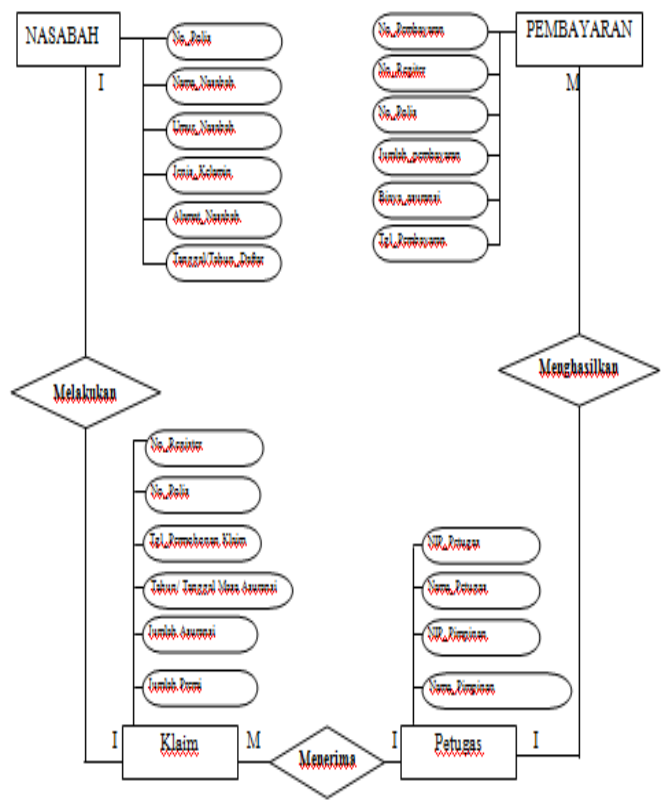

3.5 Perancangan input Sistem Informasi Klaim Asuransi Jiwa Pada PT. Jiwasraya Bandar lampung.

3.5.1 Perancangan Input Data Nasabah

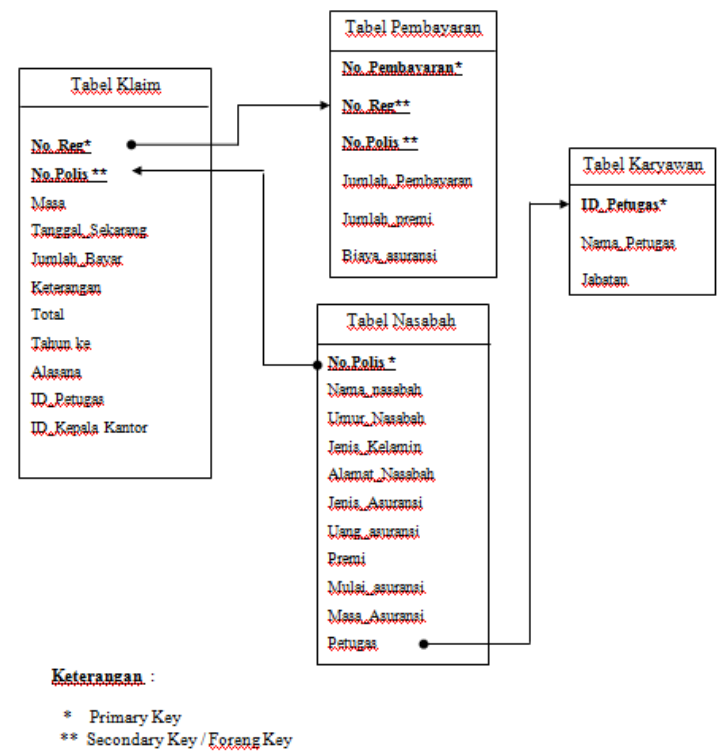

3.5.2 Perancangan Input Data Karyawan dan klaim nasabah 


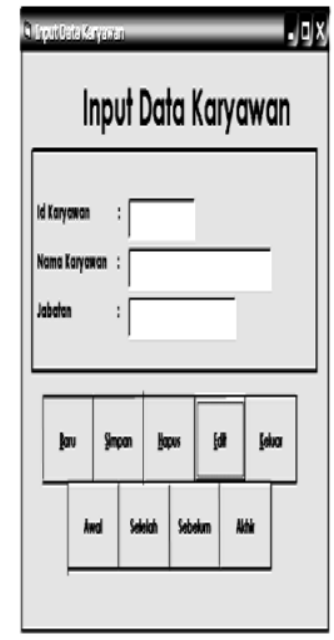

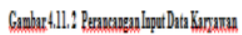

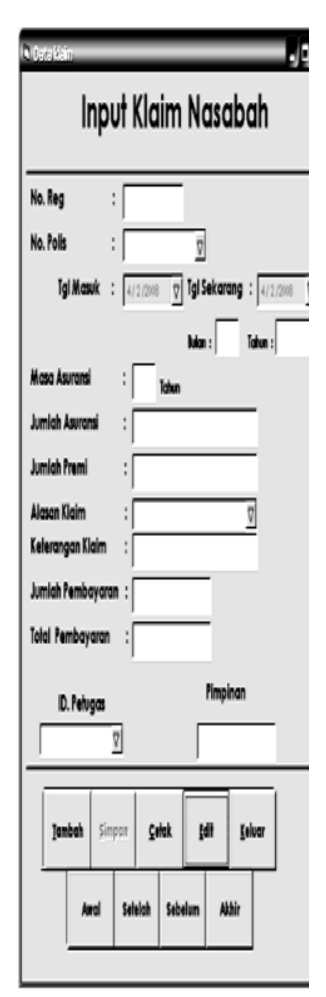

Sistem Informasi Klaim pada PT. Jiwasraya akan memberikan kemudahan kepada nasabah dalam melakukan permohonan klaim.

2.Adanya aplikasi dapat membantu petugas bagian klaim sehingga dapat dengan cepat dalam melayani pasien yang akan mendaftar.

\subsection{Saran}

Disamping beberapa kesimpulan tersebut, penelitian juga mencoba memberikan saran yang diharapkan dapat bermanfaat bagi PT. Jiwasraya , terutama pada bagian Klaim.

Adapun saran tersebut adalah :

* PT. Jiwasraya hendaknya dapat mempergunakan sistem yang diusulkan untuk mengolah data Penebusan Klaim karena kemampuan kerja aplikasi ini lebih efektif dan efisien .

Agar aplikasi ini dapat berjalan dan berfungsi sebagaimana mestinya, maka diperlukan tenaga petugas yang hanya bertugas pada bagian Klaim di PT. Jiwasraya Kota Bandar Lampung.

\subsubsection{Perancangan Input Data Pembayaran}

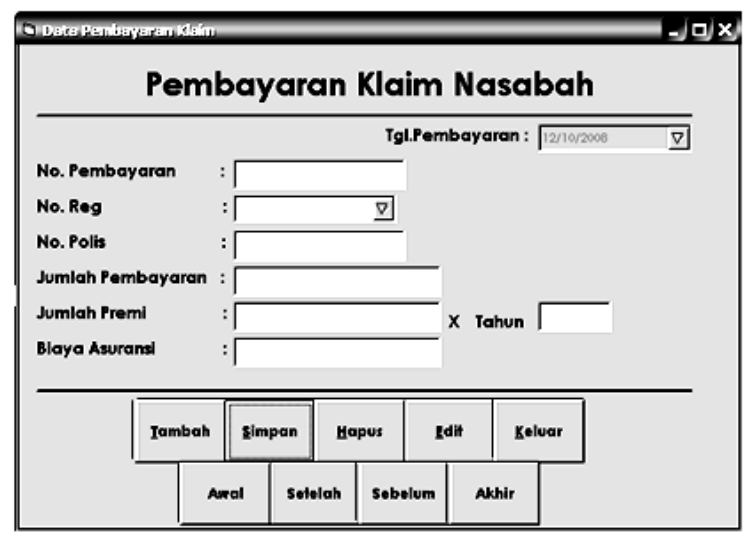

\subsection{KESIMPULAN DAN SARAN}

Dari hasil penelitian yang telah dibuat di atas pada bagian terdahulu, maka penelitian dapat mengambil kesimpulan dan saran yang dikaitkan dengan perancangan Sistem Informasi Penebusan Klaim Pada PT. Jiwasraya Kota Bnadar Lampung, sebagai berikut.

\subsection{Kesimpulan}

Berdasarkan pada bab - bab sebelumnya, maka peneliti mengambil kesimpulan sebagai berikut :

1. Dengan adanya sistem baru berpa bahasa pemrograman Microsoft visual Basic 6.0 dalam 